University of Nebraska - Lincoln

DigitalCommons@University of Nebraska - Lincoln

1992

\title{
Self-Management and Team-Making in Cross-Functional Work Teams: Discovering the Keys to Becoming an Integrated Team
}

Mary Uhl-Bien

University of Nebraska-Lincoln, mbien2@unl.edu

George B. Graen

University of Cincinnati

Follow this and additional works at: https://digitalcommons.unl.edu/managementfacpub

Part of the Management Sciences and Quantitative Methods Commons

Uhl-Bien, Mary and Graen, George B., "Self-Management and Team-Making in Cross-Functional Work Teams: Discovering the Keys to Becoming an Integrated Team" (1992). Management Department Faculty Publications. 40.

https://digitalcommons.unl.edu/managementfacpub/40

This Article is brought to you for free and open access by the Management Department at DigitalCommons@University of Nebraska - Lincoln. It has been accepted for inclusion in Management Department Faculty Publications by an authorized administrator of DigitalCommons@University of Nebraska - Lincoln. 


\title{
Self-Management and Team-Making in Cross-Functional Work Teams: Discovering the Keys to Becoming an Integrated Team
}

\author{
Mary Uhl-Bien, University of Alaska at Anchorage \\ George B. Graen, University of Cincinnati \\ Corresponding author - Mary Uhl-Bien
}

\begin{abstract}
Project teams are rapidly becoming the primary mechanisms for innovation and change in modern organizations. As such, they are designed to capitalize on leadership and integrated cross-functional teamwork and to negate subordination and individual gamesmanship. Unfortunately, research on crossfunctional project teams is scarce and largely atheoretical. The increasing use of these project teams by modern organizations, however, calls for theory development in this area. In the present paper, self-management and team-making models are applied to cross-functional project designs to develop a theoretical framework for the investigation of teamwork effectiveness for integrated cross-functional project teams. Future issues for theory development and research methodology are presented.
\end{abstract}

Modern organizations must deal with new and more complex international environments, in which unstructured problem-solving throughout the organization is becoming the rule rather than the exception (Trist, 1977; Cummings, 1978; Manz \& Sims, 1984; Walton, 1985). As a result, organizational members are faced with increasingly complex task requirements, necessitating the use of non-traditional problem-solving organizational designs (Mohrman \& Cummings, 1989; Goodman, Devadas, \& Hughson, 1988). To deal with the demands of this environment, organizations are finding it necessary to move from a traditional, single discipline work group structure to a multi-discipline project group structure, 
where members from different functional areas join together in multidisciplinary project teams to discover integrative solutions to complex, unstructured tasks (Starr, 1988; Bertodo, 1988; Whitney, 1988).

More than complex, unstructured tasks, however, multi-functional project teams are necessary to deal with problems of "organized complexity" - those problems which cut across functional areas and for which multiple but independent functional solutions are not adequate. These problems of "organized complexity" require the integration of input from members of multiple functional areas. Thus, in contrast to problems of "disorganized complexity," which can be partitioned into single discipline components, solved, and assembled to produce a whole solution, problems of organized complexity require that individuals from several functional areas work together throughout the problem-solving process to produce integrated multi-functional definitions and solutions to problems.

The use of a multi-functional project approach for solving problems of organized complexity is very different, however, from traditional single discipline problem-solving techniques. Since cross-functional project structures are becoming increasingly popular in the management of modern organizations (Hessel, Mooney, \& Zeleny, 1988; Drucker, 1988), it is important that these differences be understood. Thus, the purpose of the present paper is to identify the unique characteristics of cross-functional, multidisciplinary project designs and to develop a framework for investigating how these types of work units may be most effectively implemented. In particular, in the following sections, the unique characteristics of multidisciplinary (cross-functional) project groups are introduced and explained, the self-managing nature of these work units is described, and applications of both self-managing (Manz \& Sims, 1989) and team-making (Graen \& Uhl-Bien, 1991) models to these types of structures are made. Following this, implications for future investigation are discussed.

\section{Multidisciplinary Work Group Structure}

While multidisciplinary project teams attend to the problem of dealing with organized complexity, they also present new problems and challenges to organizational managers (Niklas, 1987; Moskal, 1988; Bertodo, 1988; Kezsbom, 1989). In particular, multidisciplinary work groups differ from single discipline work groups in that they are comprised of members with different technical backgrounds (see Figure 1). Similar to a matrix structure (Galbraith, 1973; Katz \& Allen, 1985), multidisciplinary team structure is based on dual assignments of organizational members to both functional areas and problem-solving teams. Thus, organizational members in this type of design structure are both members of the discipline section of their technical specialty as well as participants in the problem-solving teams. Individuals may be involved in one or more project teams at a time, while continuing to report to their discipline section. As a result, members operating in this design system may have multiple reporting relationships. For example, they may report to the discipline head of their respective section as well as to project leaders on any project in which they are involved (see Figure 1). 


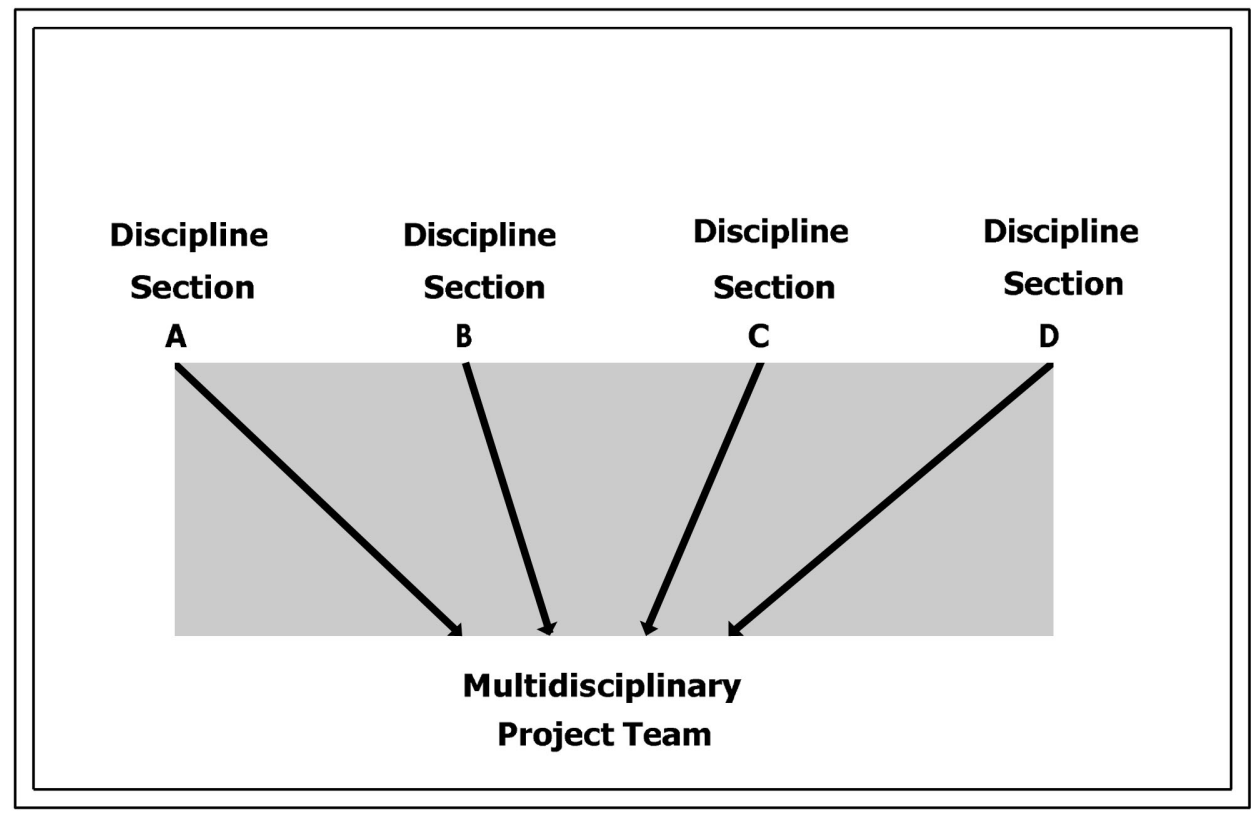

Figure 1. Multidisciplinary Project Team Composition

\section{Leadership}

Because of the unique structure of multidisciplinary work teams, leadership of these teams differ from traditional "managership" models used in many single discipline work group structures. In many cases, project leaders who are assigned to the teams may not be able to provide technical guidance or evaluation to team members since they may not have sufficient technical expertise in the areas of each team member (Niklas, 1987). Instead, any technical assistance which team members required would have to be obtained from their discipline section. Because of this, managership, which involves directing based on superior expertise and authority, is not possible within these types of work teams. Instead, coordination and facilitation of these projects requires the use of "leadership," where teamwork effectiveness is based on persuasion and incremental influence (Katz \& Kahn, 1978) about the utility of achieving group goals.

Distinctions between managership and leadership are shown in Table 1. As indicated in the table, managership is employed to direct and control people assigned to prescribed jobs, and who use resources following established routine to perform business as usual. Managership requires that elaborate communication and control procedures be available to ensure role compliance. In contrast, leadership is employed to give people the opportunity and challenge of innovation 
Table I. Differences Between Managership and Leadership

\begin{tabular}{|c|c|c|}
\hline & Managership & Leadership \\
\hline WHERE: & Jobs & Projects \\
\hline WHEN: & Business as Usual & Innovation and Change \\
\hline WHY: & Overdetermine Routine & Create Integrated Teamwork \\
\hline HOW: & $\begin{array}{l}\text { Efficient Use of Rules and } \\
\text { Resources }\end{array}$ & $\begin{array}{l}\text { Transformation of Self-Interest into } \\
\text { Team-Interest via Incremental Influence }\end{array}$ \\
\hline COST: & $\begin{array}{l}\text { Elaborate Communication } \\
\text { and Control }\end{array}$ & Investment in Relationships \\
\hline BENEFIT: & Role Compliance & Continuous Improvement \\
\hline
\end{tabular}

and change through integrated teamwork on projects. Leadership requires that investment in relationships be made to transform self-interest into team-interest via incremental influence, so that continuous improvement can be internalized.

Thus, although leadership can be employed within a designated job context with difficulty, managership is nearly always inappropriate in a project context. When leadership is used within a job context, it is restricted to helping people outgrow their jobs. Clearly, the goals of the two processes are incompatible: role compliance requires religious conformity to established rules and procedures, while continuous improvement implies innovation and change in rules and procedures. In terms of multidisciplinary project teams, effective project management comes from leadership - the earning of interpersonal incremental influencewhere team members are motivated not by formal role definitions or because it's their "job" (in fact, if members follow their formally defined roles the system will probably shut down) but because they have been persuaded to accept and commit to the goals of the team. Thus, multidisciplinary project leadership involves more coordination and communication facilitation activities as well as earning of incremental influence by the project leader (and team members with each other) than supervision (Heany, 1989; Mohrman \& Cummings, 1989; Sayles, 1989; Graen \& Uhl-Bien, 1991).

Moreover, because project leaders in many cases would not be able to provide technical supervision over team members, this role would have to be performed by the team members for themselves. Multidisciplinary team members would thus become responsible for monitoring and managing their own behaviors with respect to their technical area. Using Hackman's authority matrix (Hackman, 1986), since the multidisciplinary nature of these work teams requires individuals to take on additional responsibility for directing their own technical behaviors within the team, these work groups may be characterized as units of self-managing individuals.

\section{Self-Managing}

According to Hackman (1986), self-management involves individuals taking responsibility for executing, monitoring, and managing their own performance 
and work processes (p. 88). In terms of the multidisciplinary project teams described above, this definition is compatible with the processes performed by the individual team members - they must execute, monitor, and manage their own performance and work processes relative to their discipline specialty. Moreover, in some cases, these work groups may also be characterized as self-managing units, where the team has responsibility for monitoring and managing its own behavior. In contrast to units of self-managing individuals, where the group members have responsibility for managing their own behavior but the group itself may not have self-managing authority, in self-managing units the members have responsibility for managing and monitoring the activities of the group.

\section{Group Characteristics}

In addition to the differences in leadership requirements of multidisciplinary work teams, another important distinction between single and multidisciplinary team functioning involves the working characteristics of the group. In contrast to single discipline work groups, multidisciplinary team members are not able to cover the work of the other team members since they do not have the technical backgrounds in all discipline areas which are represented on the project team. Because of this it is important that all team members contribute to the work of the project team. Given that the technical area which the individual represents is considered to be important for the effectiveness of the team (or else that area would not have been represented), the failure of a team member to contribute to the team means the lack of potentially vital information - information which may not be provided by any other source.

Hence, unlike single discipline work groups, multidisciplinary project assignments may not be redundant in the sense of being performed by more than one team member. Thus, all team members must represent their area of expertise by contributing to project requirements. Individual team members become responsible for their own area of expertise and their collaboration with other team members to integrate their discipline area into the problem-solving processes of the project team. Moreover, since information is coming from a variety of sources, integration of the information provided by each discipline representative on the team into a cohesive final product requires team members to work together using teamwork processes. These teamwork processes are based on the potential of the team members to act as team players - to be committed to the goals of the team and engage in those activities that will be most beneficial for a successful team outcome.

One obstacle which often prevents effective teamwork processes in multidisciplinary work teams, however, is the increased potential for conflict in these groups (Brown, 1983; Heany, 1989). This conflict is not only between team members but also internal conflict within a team member, and arises from the differences in goals among the separate functional areas of the members and the overall multi-functional goals of the cross-disciplinary team. In particular, differences in goals of the individual members may lead to bickering and in-fighting among 
team members, as each acts to represent his or her own individual interests. It may also lead to internal conflict within the team members themselves, as they struggle to determine which goals they will prioritize - the goals of the team or the goals of their discipline section.

In order for the team to be most effective, however, it is necessary for the team members to set aside their more separate interests and accept the overall, common goal of the team (which, as discussed later, results from the use of real "leadership" within the team). In doing this, the members realize that the most effective way for them to function successfully as an organization is to work together to attain solutions that will best serve the needs of the multiple discipline sections, rather than a selected few. Thus, effective teamwork processes require that the team members be committed to the overall goals of the team - that they become committed team players. Once this has occurred, it is this overall goal which becomes the driving force of the team and that subsequently provides the direction to the work of the team.

Compared to single discipline work groups, therefore, cross-functional work groups provide unique opportunities to researchers interested in investigating teamwork processes. Since team members must collaborate closely to integrate information from various technical perspectives, it is necessary for cross-functional team members to act as team players and to work together using integrated teamwork processes for the task to be successfully completed. If a multidisciplinary project is successfully completed, we may assume that both leadership and integrated teamwork have occurred. In single discipline work groups, on the other hand, unit effectiveness does not necessarily indicate either leadership or integrated teamwork, since it is possible for individual members to perform the task for the entire group - without real leadership or integrated teamwork processes occurring at all. Thus, since effective multidisciplinary work group structures require real leadership and unique teamwork processes, we turn next to a discussion of cross-functional work group processes.

\section{Cross-Functional Work Group Process}

\section{Core Team}

In order to understand teamwork processes within a cross-functional team, it is first necessary that we be able to identify the core team. This is particularly important for multi-functional project teams, which are often comprised of a central core group responsible for the primary processes within the team, and support players, who perform auxiliary functions for the team but are not directly involved in the primary decision-making processes of the group. The core group is generally stable, and will remain principal members of the team throughout the duration of the project, whereas support people may rotate in and out of the project as deemed necessary by the changing nature of the work. Thus in terms of identifying the actual team, or those individuals who are most 
directly responsible for the output of the group, one must look to the central core of individuals directly responsible for the decision-making and production of the project.

\section{Transformation}

Within this central core, it is necessary for the team members to engage in effective teamwork processes for the team to be successful. Once again, the types of teamwork processes necessary for effective team performance differ from traditional conceptualizations of teamwork. In particular, the complexities of multidisciplinary problems require that for the most effective creative problemsolving to occur, team members must go beyond simple interaction among core participants to integration of their different perspectives. Specifically, effective teamwork within this type of structure involves individuals integrating their contributions for the best outcomes of the team. In truly effective teams this integration process is accompanied by a team transformation, where the team members experience a transformation at the team level from selfish functional specialty interests to team interests (Burns, 1978). Through this team transformation, team members realize that they can most effectively accomplish their individual self-interests by ensuring that the team is successful. When this occurs, the team members, at least temporarily, place team interests above their functional self-interests, and team problem-solving moves beyond narrow specialty concerns to a combined focus on interests of all functional areas. (How this transformation [Burns, 1978] is brought about through leadership and not managership is discussed later in the paper.) It should be noted that it is this transformation to a focus on team goals over discipline area goals where the team members become committed team players.

\section{Leadership by Influence}

In effective multidisciplinary teams, where individuals are able to integrate ideas across functional areas and where team interests are placed above individual functional interests, the potential for creative problem-solving is greatly enhanced. Rather than "creative" ideas being individually generated and guided by the individual's disciplinary perspective and self-interest, the idea-building process may occur freely and from a variety of perspectives, where each functional specialty builds upon the best ideas of the other. Moreover, due to the self-managing nature of the team and the need for each member to engage in leadership processes at some point throughout the problem-solving process, leadership processes within multidisciplinary team structures involve rotating leadership by expertise (Alston, 1986). Rather than a rigid hierarchical structure, with each individual assigned certain roles within which they are expected to remain, multidisciplinary team structures are more organic in nature, with team members taking on different roles (including leadership roles) according to the changing needs of the problem situation. 


\section{Summary}

Thus, in multidisciplinary teams, where success is based on creative, crossfunctional problem solving, effective teamwork involves integration of functional ideas into multi-functional solutions by core members of the team who have become committed team players who place successful team performance as a priority over their individual functional interests. Mentioned previously, this type of teamwork involves team members asserting self-managership and leadership when the situation requires. In addition, effective teamwork is significantly influenced by the types of leadership relationships team members have with each other. Finally, the most effective multidisciplinary teamwork requires a team transformation, through which the individual members break out of their own functional areas to take on a cross-functional perspective with respect to the problem-solving issues - thus becoming committed team players. In the following paragraphs, each of these issues is discussed in terms of how we may more successfully develop and lead multidisciplinary project teams.

\section{Self-Management in Multidisciplinary Teams}

An area of investigation that has recently been developed in the organizational literature, and that may have implications for multidisciplinary teamwork effectiveness, is the study of self-managing models of organizational behavior (Bandura, 1977; Cummings \& Griggs, 1977; Luthans \& Davis, 1979; Kanfer, 1980; Manz \& Sims, 1980; Mills, 1983; Frayne \& Geringer, 1987; Goodman et al., 1988; Frayne \& Latham, 1989; Manz \& Sims, 1989). Research interest in this area has been increasing in recent years because of the practical usefulness of these models for sustaining organizational competitiveness. For example, Walton (1985) has identified self-managing organizational designs as key factors in sustaining competitive advantage in contemporary markets because of their emphasis on a commitment-oriented approach to management. According to Walton, commitment-oriented models will replace traditional control-oriented models, which can produce outcomes that subvert the interests of both organizations and the people who work in them. As a result, organizations in the future will rely heavily on member self-management, because of its commitment-rather than control-orientation, for pursuing collective objectives.

Self-management models emphasize commitment-oriented approaches through their focus on self-, not external, control over one's behavior (Bandura, 1977; Luthans \& Davis, 1979; Manz \& Sims, 1980; Mills, 1983). This self-control results from the individual having responsibility not only for executing the task, but also for monitoring and managing their own performance (Hackman, 1986). Because of the additional responsibility accepted by the self-managing individual, in self-managing jobs, many functions traditionally reserved for a manager become the responsibility of a direct report. Self-managing individuals thus take personal responsibility for the outcomes of their work, monitor their own per- 
formance continuously, manage their own performance, take corrective action when necessary, actively seek from the organization the guidance, help, or resources they need for excellent performance, and take initiatives to help people in other areas improve their performance (Hackman, 1986). Stated differently, basic self-managing skills include: problem assessment, self-goal setting, self-rehearsal, self-observation and evaluation, and self-reinforcement or punishment (Bandura, 1977; Manz \& Sims, 1981).

As stated previously, these are all activities in which multidisciplinary team members must engage for a project to be successful. Given that multidisciplinary teams operate in a self-managing fashion, therefore, what implications do selfmanaging models have for teamwork effectiveness in multidisciplinary work teams?

When considering implications of self-managing models for teamwork processes, effective teamwork is proposed to be a result of the effective use of selfmanaging activities by individual team members (Hackman, 1986; Manz \& Sims, 1989). In other words, those individuals who are better able to practice self-management will contribute more positively to overall teamwork effectiveness than those individuals who do not practice self-management as effectively. Effective self-management may be characterized by the use of certain self-managing activities (Mills, 1983; Manz \& Sims, 1981). These self-managing activities include behaviors which contribute to their development on the job and their ability to perform their tasks on their own (Manz, 1986), and include the items described above. Thus, one research implication of the self-managing literature for future investigation of multidisciplinary team functioning is that multidisciplinary team functioning will be more successful when the members of the project team are able to effectively act as self-managers.

One problem with this implication of the self-managing literature for multidisciplinary project team functioning, however, involves the issue of how these individually-focused "self-managers" may be successfully transformed into an integrated group. By its very nature, self-management/self-leadership emphasizes independence: individuals are encouraged to engage in problem-solving, goal-setting, feedback-seeking processes, etc., on their own rather than as a group. As long as these individuals are performing with the intent of attaining team goals, and thus are willing to integrate their individually-generated contributions into the overall functioning of the team, self-managing processes would appear to be beneficial to group performance. A commitment to team goals over individual goals by the self-managers may not be assumed, however. Rather, if team members are engaging in self-managing activities with little regard for team goals, it is very possible that they are off working in their own direction, and are not participating effectively in integrated teamwork processes. In fact, some of the most effective self-managers may be so intent on performing on their own that they are not able to work effectively in an integrative setting with others.

Thus, the use of self-managing measures as they are currently operationalized may actually over-emphasize the individualistic nature of team mem- 
ber functioning, and generate team members who are very effective at functioning on their own, but who may not be the most committed team players. Consequently, researchers investigating self-management processes in crossfunctional project teams who place a strong focus on self-management without concurrent consideration of commitment to team goals and the teamwork orientation of the team members will likely find that self-management does not generate integrated teamwork outcomes. In situations where the self-managers are very individually focused and not willing to make the sacrifices involved in operating as part of the group, researchers may even find that self-management processes are dysfunctional to project team performance (Uhl-Bien, 1991).

One must be careful, therefore, in applying self-management concepts at the collective level. Although self-management processes may be beneficial to an individual's performance, when considered in a group setting they may not necessarily be conducive to team performance. This is particularly true when considering cross-functional project teams, where the individualistic nature of self-managing measures does not address the need for integrated, collaborative work processes. In fact, this was found in a study of the same technical people in both single- and multidisciplinary work teams (Uhl-Bien, 1991). In this investigation, self-management activities contributed positively to team performance for single discipline work groups, where the work of the unit could be effectively completed on an individual "coacting" basis, but self-management did not contribute to cross-functional team performance, and in fact appeared to be dysfunctional to team processes for these work units.

Thus, given the criticality of integrated, collaborative teamwork processes among cross-functional team members for successful multidisciplinary team outcomes, the implications of self-managing models for teamwork outcomes for these groups must be modified to address the extent to which the team members are engaging in self-managing processes for their own self-interests or for the good of the team. Although self-managing activities do indicate the potential for team members to contribute to team outcomes, as mentioned previously, commitment to team goals provides direction to the self-managers' efforts. Without this direction, a form of chaos may result in the team, with team members focusing their efforts in many different directions.

Thus, the application of self-managing models alone to multidisciplinary work groups is not adequate to explain teamwork effectiveness issues. Rather, consideration must be given to the manner through which the team members, acting as "self-managers," may be transformed into committed team players. But how is this team transformation achieved? In the following sections, team-making concepts, which describe the developmental processes through which team-building is accomplished, are presented and discussed in terms of their implications for team transformations. First, however, the team transformation process is more fully described. 


\section{Team Transformation Process}

As mentioned previously, within multidisciplinary project teams, team members must integrate information from each technical area, and the failure of a team member to contribute means a lack of representation of that member's technical area in the final decision. This could be devastating if the inadequate input results in a loss of potentially vital information. More than this, however, team members are required to accept additional responsibility for their performanceresponsibility which goes beyond traditional work roles. In addition, they must work together to move out of their more narrowly defined functional specialty to approach problem-solving from an integrative perspective. This involves developing the types of relationships within the team which will allow each member to be open to and supportive of the suggestions of the others. Most importantly, however, effective multidisciplinary teamwork involves a team transformation, in which the core group, composed of an interlocking set of members with established high involvement roles, has internalized the goals of the team and accepted these goals as the first priority for the work of the team.

As shown in Figure 2, these transformations involve a shift in primary motivation from self-interest to team-interest. Team members who have not been transformed place their primary emphasis on promoting themselves as well as the ideas of their own functional area. For example, one common obstacle to effective teamwork for multidisciplinary teams is the problem of the individual team members "protecting their turf" (Heany, 1989). Similarly, within any type of group process, the progress of the group is often hindered by conflicting goals among the team members and lack of agreement about what team goals should be (Brown, 1983). Within this type of team, the roles of team members become

\section{Primary Motivation}

Self-Interest

Team-Interest

Individual

Core Team

(Written Rules) (Unwritten Rules)

Figure 2. Transformation Processes 
specified by their functional area and by their own individual intentions. Thus, when the motivation of the team members is to satisfy their own self-interest (i.e., functional interest), their activities become specified by the role they must adopt to attain their individual goals, and each person on the team thus becomes a "role-specified" player.

When, however, the primary motivation shifts to a focus on team interest, the team members expand beyond their individual, functional goals to an adoption and internalization of team goals. In this situation, the individual team members agree that in some cases it is necessary to subordinate the goals of their functional areas to achieve an outcome that is for the good of the team. When this occurs, the behaviors of the individual team members go beyond the role-specified activities dictated by their individual and functional interests to more team-committed activities.

When a successful transformation is accomplished, its effect is to convert a role-specified team, where the individual team members are all caught up in "specialist traps" (Graen, 1989), to an integrated team, where the team members take risks by assuming additional activities outside of their functional roles to ensure that the best interests of the team are represented. This involves risk on the part of the team players, who must venture out of their more secure functional areas into a situation where they may not be as sure of what they are doing and where their roles are not as well defined. It also requires greater effort on the part of the individuals and the team, since it is more difficult to achieve an integration of many perspectives than it is for each member to focus solely on their own perspective-it requires them to think in new ways. Because of this, for a transformation to occur at the team level, the team members must recognize that it is only through integration of input from multiple areas that they may achieve a more beneficial outcome than if they had worked individually. Thus, for multidisciplinary project teams to effectively achieve teamwork processes and team outcomes, it is necessary that a team transformation occurs at both the individual and team levels. How this team transformation may be achieved through a process of team-making is described below.

\section{Team Transformation Through Team-Making}

One theoretical model which contributes to our understanding of the transformation at both the individual and team levels is the team-making model (Graen \& Uhl-Bien, 1991). This model uses a developmental approach to teammatebuilding to illustrate how effective team leadership may be developed within the group. In particular, the model is based on the premise that effective leadership, which must ultimately occur at the group level, evolves over a life cycle and can transform a group of acquaintances performing only their role-specified duties into an integrated team of teammates.

Briefly stated, the team-making model describes how effective (or mature) leadership relationships between teammates are developed between group mem- 
bers. This team-making occurs during a three-phase process (Graen, 1989), in which a series of reciprocal commitments are made between the individuals involved. (Note: It is important to recognize that the team-making model applies to any of the interrelationships among the team members, including horizontal, vertical, and diagonal dyadic relationships, and that it is a special use of role-making within teams.)

The first phase, team-finding, involves the initial testing process through which the team members evaluate each others' motivations and abilities. This is a "sampling" phase, wherein each person attempts to discover the relevant team talents and motivations of the others, as well as to identify the resources the others have to offer. This process unfolds through iterative testing sequences. By offering various opportunities to the others, a team member can successively approximate the performance limitations of teammates, as well as other dimensions relevant to team identity. Moreover, by demonstrating a desire to expand beyond their rolespecified behaviors, each can determine the extent to which others are willing to forego their own special interests to consider the larger interests of the team. By engaging in these "testing" activities, in a very short period of time, a group may learn a great deal about their constituents. The results of this team-finding phase subsequently influences the next stage of relationship development - the teamdesigning phase.

Based on the results of the evaluative tests conducted in the team-finding phase, the group may remain at a relatively low level of change (if the results of the testing process are negative), or they may progress to more advanced stages of change (if the results of the testing process are positive). How this development will occur is determined in the team-designing phase. During this phase, the team members evolve how each will behave in various situations and begin to define the nature of their team relationships. This process is explicitly discussed by team members, and through working together, they test various team interdependencies as alternatives to role-specified team problem-solving approaches. Consequently, new sets of interlocked behavior cycles that are mutually reinforcing emerge. In these team-designing episodes, any of the teammates may initiate a sequence. Hence, through a series of suggestions and counter-suggestions, a set of understandings governing appropriate team roles is developed.

Team-designing depends on the mutual investment of valued resources by all parties. Each party invests something the team values, and each party sees the exchange as reasonable. Moreover, the rules governing the team relationship must be compatible to result in a high level of mutual trust and team commitment. Without adequate trust, the process grinds to a halt or is never initiated because the acceptance of team collaboration becomes too risky for members. Without the collaboration of the team members, the individual member is typically in over his head and cannot proceed. For example, in terms of the self-managing teams described above, this collaboration with teammates and influential others (i.e., discipline section leaders and coworkers, etc.) is essential for members to accept the risks inherent in becoming part of a self-managing team. 
After defining the characteristics of the relationship in the team-designing phase, the behaviors of the team becomes interlocked during the team-transformation phase. It is during this stage that the team members actually learn to collaborate effectively as a team by placing team interests above their own self-interests. As they work together, they make changes in their team roles - those coordinated behaviors that are judged effective tend to be strengthened, whereas those that are seen as ineffective tend to be weakened.

In this phase, effective interpersonal relationships mature from acquaintances to established teammates. Mutual trust, respect, loyalty, understanding, and commitment are developed. The relationship with the team is transformed from simple exchange of self-interest outcomes for compliance with a specified role to one of commitment to an integrated team, where each promotes the other's team interests through a commitment to integrate their contributions for the best outcomes of the team. In other words, something larger than immediate self-interest of all parties becomes the driving force of the team. It is at this point that a rolespecified team has evolved into an integrated team.

Thus, through team-making, the team transformation process may be achieved. By developing mature relationships with their teammates and influential others, team members receive the resources, support, and guidance necessary to effectively engage in teamwork processes. Moreover, by receiving the additional resources and support from teammates and influential others, the team members are given the proper contextual conditions for effective self-management to occur. These implications of team-making for both teamwork and self-management processes indicate that the team-making model provides a useful vehicle for the development of multidisciplinary work teams.

Hence, the team-making model, which involves development of integrated teams of teammates and generation of incremental influence, has strong implications for both modern organizations and for the management of multidisciplinary work groups. By developing such teams, project leaders and team members are able to achieve the conditions necessary for effective teamwork and self-management processes to occur. In particular, the greater openness and acceptance between high maturity teammates and influential others allows team members to obtain the necessary resources, support, assistance, and guidance that are so vital to successful performance by multidisciplinary, self-managing work teams. The team-making model, therefore, when taken in combination with self-management models, provides a theoretical groundwork through which effective management of multidisciplinary work teams may be more thoroughly investigated.

\section{Implications and Conclusion}

The application of self-management and team-making to cross-functional project team designs has implications for both future research and theory development concerning multidisciplinary team functioning. First, the implications of 
self-managing models suggest that incorporation of self-management concepts into investigation of multidisciplinary team processes may provide new insight into contributors to successfulness of these teams. In particular, specific research implications of these models suggest that the ability of multidisciplinary team members to effectively act as self-managers will influence the overall effectiveness of the team when these members are also committed team players.

Second, team-making models stress the importance of high involvement team-making for teamwork effectiveness within these work structures. Implications of the team-making model suggest that: (1) high involvement team-making between team members and their respective discipline heads and project leaders will contribute positively to teamwork effectiveness outcomes, (2) high involvement team-making between team members and their teammates as well as with their discipline section coworkers will positively affect team outcomes, and (3) high involvement team-making between team members and influential others outside the team (i.e., competence networks and team sponsors) will positively impact on team performance. The roles developed in this team-making will influence team outcomes through their impact on the amount of resources, support, trust, and openness of communication available to the members of the team.

Finally, the team-making model provides a framework through which development of self-management and team transformations may occur within multidisciplinary designs. Through a three-phase model of relationship-building, the team-making model describes the process through which incremental influence is earned in teams and teammate-building is achieved. In particular, by progressing from team-finding through team-designing to team-transformation, team members are able to experience the transformation from self-interest to team-interest, where the activities of the team are focused on integration of contributions from each functional area into a cohesive and mutually beneficial final product. By successfully completing the three phases, an interlocking set of mature relationships develops, where all individuals are able to rely on each other for the mutual trust and support that allows each team member to most effectively represent the contributions of his/her functional area.

Overall, the application of these models provides a groundwork for research and development in this area. Future research should focus on testing the implications of these models (when taken in combination) for their ability to predict team outcomes for these types of structural designs.

\section{Summary}

Modern organizations are increasingly being confronted with problems characterized by organized, multi-discipline complexity. Such problems require the creative use of multidisciplinary project teams, which can integrate the problemsolving power of several different disciplines. These project teams are the mechanisms for innovation and change in modern organizations. As such, they are de- 
signed to capitalize on leadership and integrated cross-functional teamwork and to negate subordination and individual gamesmanship. Unfortunately, our understanding of such teams is woefully inadequate, and development models of such groups are likely to be very different from those models which have traditionally been used with single discipline groups. To attempt to begin theoretical development in this area, in the present paper multidisciplinary team processes were examined in terms of their unique teamwork requirements, and several existing organizational behavior models were applied for their implications for theory- building. Specifically, multidisciplinary structural designs were examined in terms of self-managing and team-making models, which were used to provide a theoretical framework for future investigation in this area.

\section{References}

Alston. J. (1986). The American samurai: Blending American and Japanese managerial practices. New York: W. de Gruyter.

Bandura, A. (1977). Social learning theory. Englewood Cliffs, NJ: Prentice-Hall.

Bertodo, R. G. (1 988) Evolution of *an engineering organization. International Journal of Technology Management, 3, 693-710.

Brown, L. D. (1983). Managing conflict at organizational interfaces. Reading, MA: Addison-Wesley.

Burns, J. (1978). Leadership. New York: Harper \& Row.

Cummings, T. G. (1978). Self-regulated work groups: A sociotechnical synthesis. Academy of Management Journal, 3, 625-633.

Cummings, T. G., \& Griggs, W. H. (1977). Worker reactions to autonomous work groups: Conditions for functioning, differential effects, and individual differences. Organization and Administrative Sciences, 7(4), 87-100.

Drucker, P. F. (1988, January, February). The coming of the new organization. Harvard Business Review (pp. 45-53).

Frayne, C. A., \& Geringer, J. M. (1987). Self-management: A key to improving international joint venture performance? International Personnel and Human Resource Management Conference Proceedings, Singapore.

Frayne, C. A., \& Latham, G. P. (1989). Self-management training for increasing job attendance: A follow-up and replication. Journal of Applied Psychology.

Galbraith, J. (1973). Designing complex organizations. Reading, MA: Addison-Wesley.

Goodman, P. S., Devadas, R., \& Hughson, T. L. (1988). Groups and productivity: Analyzing the effectiveness of self-managing teams. In J. P. Campbell, R. J. Campbell, \& Associates (Eds.), Productivity in organizations. San Francisco: Jossey-Bass.

Graen, G. (1989). Unwritten rules for your career: 15 secrets for fast-track success. New York: John Wiley \& Sons.

Graen, G., \& Uhl-Bien, M. (1991). The transformation of professionals into self-managing and partially self-designing contributors: Toward a theory of leadership-making. Journal of Management Systems, 3(3), 33-48.

Hackman, J. R. (1986). The psychology of self-management in organizations. In M. S. Pollack \& R. O. Perloff (Eds.), Psychology and work: Productivity, change and employment (pp. 
85-136). Washington, DC: American Psychological Association.

Heany, D. F. (1989). Cutthroat teammates: Achieving effective teamwork among professionals. Homewood, IL: Dow-Jones-Irwin.

Hessel, M., Mooney. M., \& Zeleny, M. (1988). Integrated process management: A management technology for the new competitive era. In M. K. Starr (Ed.), Global competitiveness: Getting the U.S. back on track. New York: W. W. Norton.

Kanfer, F. H. (1980). Self-management methods. In F. H. Kanfer \& A. P. Goldstein (Eds.), Helping people change: A textbook of methods (2nd ed., pp. 271-280). New York: Pergamon Press.

Katz, R., \& Allen, T. J. (1985). Project performance and the locus of influence in the R\&D matrix. Academy of Management Review. 28. 67-87.

Katz, R. \& Kahn, R. L. (1978). The social psychology of organizations (2nd ed.). New York: John Wiley \& Sons.

Kezsbom, D. S. (1989). Managing the chaos: Conflict among project teams. AACE Transactions (pp. A.4.I-A.4.8).

Luthans, F., \& Davis, T. R. (1979). Behavioral self-management: The missing link in managerial effectiveness. Organizational Dynamics, 8, 42-60.

Manz, C. (1986). Self-leadership: Toward an expanded theory of self-influence processes in organizations. Academy of Management Review, 11, 585-600.

Manz, C., \& Sims, H. (1980). Self-management as a substitute for leadership: A social learning theory perspective. Academy of Management Review. 5, 361-367,

Manz, C., \& Sims, H. (1984). Leading self-managed groups: A conceptual analysis of a paradox. Economic and Industrial Democracy, 7, 141-165.

Manz, C., \& Sims, H. (1989). Superleadership: Leading others to lead themselves. Englewood Cliffs, NJ: Prentice-Hall.

Mills, P. (1983). Self-management: Its control and relationship to other organizational properties. Academy of Management Journal, 8, 445-453.

Mohrman, S., \& Cummings, T. (1989). Self-designing organizations: Learning how to create high performance. Reading, MA: Addison-Wesley.

Moskal, B. S. (1988). Managing in the 90's: Tomorrow's best managers - Where are they now? (Part 2). Industry Week, 237, 32-34.

Niklas, G. (1987). Self-managing teams and unions. Quality Circles Journal, 10, 36-40.

Sayles. L. R. (1989). Leadership: Managing in real organizations (2nd ed.). New York: McGraw-Hill.

Starr, M. (1988). Global competitiveness: Getting the U.S. back on track. New York: W. W. Norton.

Trist, E. (1977). Collaboration in work settings: A personal perspective. Journal of Applied Behavioral Sciences, 13, 268-278.

Uhl-Bien, M. (1991). Teamwork of the future: An investigation into teamwork process for professional work teams in knowledge-based organizations. Unpublished doctoral dissertation, University of Cincinnati.

Walton, R. (1985). From control to commitment: Transformation of workforce strategies in the United States. In K. Clark, R. Hayes, \& C. Lorenz (Eds.), The uneasy alliance: Managing the productivity-technology dilemma (pp. 237-265). Boston: Harvard Business School.

Whitney, D. E. (1988). Manufacturing by design. Harvard Business Review, 66, 83-91. 